\title{
The Virtual Museum in Educational Practice
}

\author{
Maria Kampouropoulou ${ }^{1}$, Persa Fokiali ${ }^{2}$, Ioanna Efstathiou ${ }^{1} \&$ Efstathios Stefos ${ }^{1}$ \\ ${ }^{1}$ Department of Primary Education, University of the Aegean, Rhodes, Greece \\ ${ }^{2}$ Department of Pre-school Education and Educational Design, University of the Aegean, Rhodes, Greece \\ Correspondence: Ioanna Efstathiou, Department of Primary Education, University of the Aegean, Rhodes, \\ Greece. Tel: 30-2241-071-566. E-mail: iefsta@aegean.gr
}

Received: June 12, 2013 Accepted: July 25, 2013 Online Published: August 20, 2013

doi:10.5539/res.v5n4p120 URL: http://dx.doi.org/10.5539/res.v5n4p120

\begin{abstract}
The educational role and social contribution of the Museums are achieved by increasing their communication with each social group and their extroversion cultural roles. They can also offer exchanges of experiences by encouraging students' audience. Because of the general world upheavals, the social contribution of the Museums has changed. The goal of this study is to appoint the students' views of a virtual educational Popular Culture Museum. In this context, a research in the third grade of junior High school in Ialyssos, Rhodes, was carried out during the school year 2012-2013. After participating in a school project concerning a construction of an educational virtual Museum, one hundred (100) students took part in the research and answered a questionnaire before and after the teaching intervention. In order to extract the research results, we used statistics software SPSS v.17 and SPAD v. 4.5, offered by the Department Education in the University of the Aegean.
\end{abstract}

Keywords: art, experiential education, sustainable development, virtual museum

\section{Introduction}

Current educational trends suggest the connection between school knowledge and children's experiences with the situations, conditions and circumstances of everyday life. This conception means new approaching methods of knowledge. Experimental learning approach is the modern pedagogical challenge. It offers the students an active role, based on educational interaction, initiative and creativity. It also emphasizes the participatory aspect in courses, turning students and teachers to co-creators during the educational process. It is mainly implemented through educational action plans (projects) within student's methodical involvement in order to convert their own studies into an interesting topic. Giving students acting ability on issues from his/her experiences, needs and interests, not only we provide knowledge that is "essentially beneficial and actually educational" (Raptis, 1983), but, we also strengthen learning availability (Birbili, 2005).

\section{Method}

The effective educational interventations should ensure the kind of education children are interested in, responding to their interests and be attractive to them. Propably there is nothing we can learn without personal motivation to do it (Rogers, 1957), except in conjuction with our experiences (Georgopoulos et. al., 2009). The new research data is focused not only in knowledge itself, but in the process of its acquisition. It supports teaching models such as experimental approach based on the needs and interests of children through peer communication relationships and involves all team members of the classroom. Teaching is a process in which both teachers and students interact and involve actively. The relationships that develop between the students are equally important, too (Kampouropoulou et al., 2003). We know that if we really want to help children to discover the world around, we should provide them opportunities for experiences by using the appropriate materials, organize activities in an appropriate social atmosphere. These experiences should become "the start point for all kind of education" (Dewey, 1941).

Experiential addresses children's individual experiences as educational material and gives them the chance to produce more knowledge compared to the traditional way if education (Dewey, 1938, 1998). The procedure of integrating experiential situations in school life and mutating in teaching activities, implements under an equal communicative relationship between educator and children (Chrysafidis, 2000). Meanwhile teachers become coordinators and help children to discover knowledge, emphasizing in their participatory aspect in order to become with the students co-creators in the learning process. Experiential learning approach is mainly 
implemented through educational action plans, in other words through project, with the involvement of students in methodical action, so the study of a topic can be interest to them (Matsagouras, 2002).The joint involvement of all team members in the individual process of the method, leads to experiences that become learning source.

In our project, students worked in three different teams. The first team visited students' and relatives' houses accompanied by teachers and took digital photos of various folk art items (such as pottery, objects of woodcarving etc.), measured their sides and interviewed the owners about the history of the items. The second team undertook the identification of the items with others, searcing in bibliography of the school library and internet suggested by the teachers. Work of the third team was the diditization of the texts/information, the transcript of oral testimonies and the digital grouping of the items in different folders. The procedure consisted four stages: (1) Isolate objects from their environment using the "gimp" image editing program (free software), (2) Virtual Museum rooms' construction where the items would be "hosted" using the PowerPoint software. Each slide of the application was stored as a picrure, (3) Image maps construction (4), Suspension on the school website as html files. During the educational activity the teachers who were responsible for the project, acted as mentors and advisors for the students at all stages and solved out any emcountered difficulties.

\section{Education of Art and Virtual Reality}

It has become increasingly clear that Arts' study may support generally education and approach of historical concepts, such as those of "change" and "conservation" (Baltas \& Demou, 2002), and also a wider prospect of emphasizing the cultural dimension of education. Since Museums host the visible part of History and Art and also testimonies that reflect aspects of material culture and natural environment, students have the opportunity to receive many messages and stimuli that contribute to learning and historical research. They can meanwhile study different areas and get envolved in learning experiences and adventures (Girtzi \& Boutidou, 2010).

The new scientific field of virtual reality has developed rapidly in the overall of technological progress, claiming Technological implementations with anthropocentric character (Archontides et al., 2004). Virtual reality is increasingly attractive to more and more both recearchers and educators at the application level in multiple disciplines. Its use is based on constructive learning theories because it is focused to the experiental knowledge and experience of students. Through their navigation and involvement by using many senses, they manage to interact with virtual environment (Mikropoulos et al., 1994; Mikropoulos, 1995).

\section{Goals of Educational Virtual Museum}

Digitizing items and exhibit them in a virtual Museum, achieves the survival, emergence and strengthening of all the elements they characterize and define the collective memory of a society. It also promotes the social, educational, cultural and economic objectives and contributes decisively to the historical cultural and scientific promotion. Virtual Museums' educational role and social contribution is achieved by increasing their communication with each social group and their extroversion cultural roles. It can also offer exchanges of experiences encouraging students' audience. The Museums' aim is to create and view "substitute" tangible and intangible assets of local art, in order to extract information related to courses taught at school. Visitors try to understand objects and learn through an active exploration (active discovery) and they are also given more opportunities for learning (Bernier, 2002).

\subsection{General Goals}

The virtual educational Popular Culture Museum was created onsite to:

- Conserve valuable information extracted through items, photographs, images, files, scripts, etc.

- Create digital educational material useful for implementation courses in school.

- Promote cultural goods through internet.

- Promote the cultural physiognomy of the local community.

\subsection{Teaching and Research Goals}

- Acquisition of general knowledge about Folklore science and espcecially students' contact with folk Art and civilazation.

- Experiental learning.

- Search of information related to items, local workshops and decoration style.

- Develop childrens' aesthetic perception, increase their imagination and abilities/skills.

- Involve students in the collection, digitization and exhibition of items. 
- Study, combinate and strengthen the role of cultural goods through available information coming from different sources.

- Study the evolution of Technology.

- Accept the high value of the ecological balance, life's quality and sustainable development through Art.

\section{Art and Sustainable Development}

One of the goals of sustainability is to preserve the cultural identity and cultural heritage. Folk Art and generally traditional culture is very important to promote childrens' attitudes and behaviors, as they are the future citizens' for sunstainability. Using the virtual educational Museum of culture, kids come in touch with folk Art and they study it. It can bring them into contact with other people and Art can be a "meeting point" to work together and improve living conditions on the planet for a sunstaiable future. As a big piece of human culture and also communication between people, Art is a part of education for sustainability and responsibility towards the environment (Fokiali \& Kampouropoulou, 2002).

The different ways of Arts enable the development of the theoretical framework of Education and Sustainability. Virtual educational Museum of Popular Culture can engage children in environmental issues and sustainability, as they are strobgly linked with culture. Art plays maybe the greatest role in redefining the relationship between man and environment (Fokiali et al., 2003).

\section{Students' Views on the Use of Virtual Educational Popular Culture Museum}

100 students of junior High school, third grade, participated in the survey before and after the teaching intervention. When asked "would you like to participate in a school project related to the preservation of Popular Culture?" a $69.00 \%$ of the students answered "yes" and 31.00\% "no" (Table 1, Figure 1).

Table 1. Variations in the question if they would like to participate in a school project related to the preservation of popular culture (pre) / if they enjoyed the participation (post)

\begin{tabular}{lcccc}
\hline & & & & Post \\
& Frequency & Percentage & Frequency & Percentage \\
\hline Yes & 69 & $69.00 \%$ & 82 & $82.00 \%$ \\
No & 31 & $31.00 \%$ & 18 & $18.00 \%$ \\
Ensemble & 100 & $100.00 \%$ & 100 & $100.00 \%$ \\
\hline
\end{tabular}

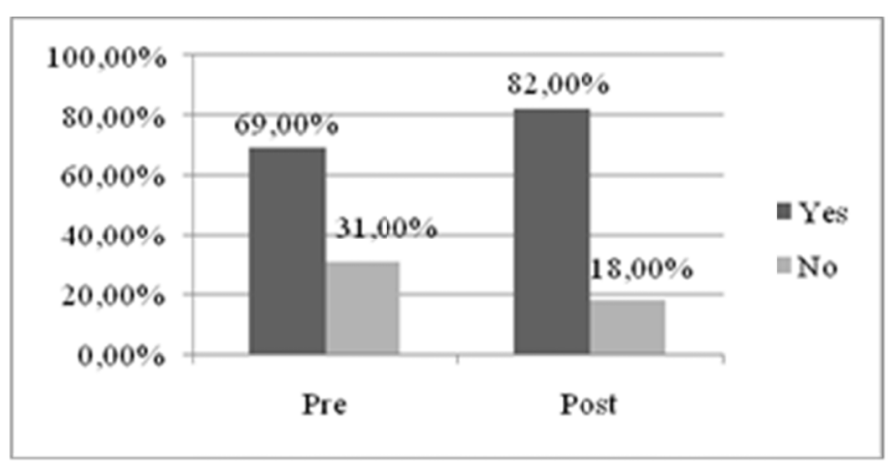

Figure 1. Would you like to participate in a school project related to the preservation of popular culture ?/ Did you enjoy your participation in the school project?

Students, when asked "do you know what local folk art is?" a $54.00 \%$ of the participants answered "yes" and a $45.00 \%$ answered "no".

After the teaching intervention $95.00 \%$ of the participants answered in the same question "yes" and 5.00\% "no" (Table 2, Figure 2). 
Table 2. Variations in the question if they know what the local folk art is, before and after teaching intervention

\begin{tabular}{lcccc}
\hline & Pre & & Post \\
& Frequency & Percentage & Frequency & Percentage \\
\hline Yes & 54 & $54.00 \%$ & 95 & $95.00 \%$ \\
No & 46 & $46.00 \%$ & 5 & $5.00 \%$ \\
Ensemble & 100 & $100.00 \%$ & 100 & $100.00 \%$ \\
\hline
\end{tabular}

As shown in Table 2, a great amount of pupils learnt more about local folk Art after their participation in the school project.

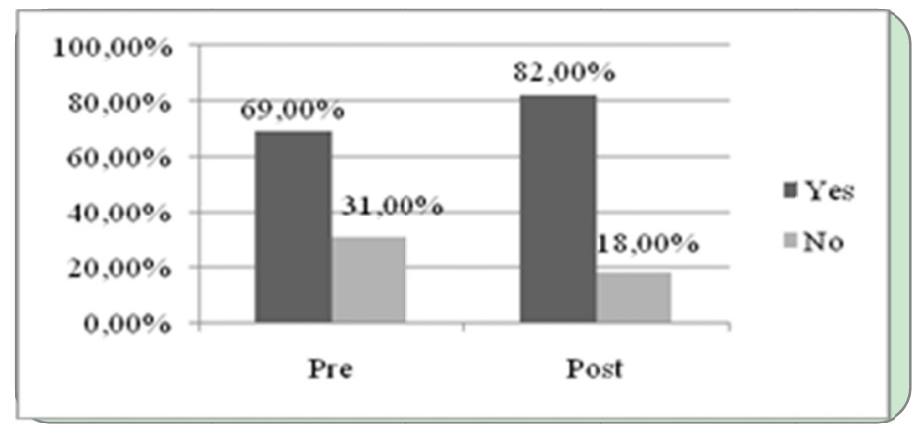

Figure 2. Do you know what local folk art is?

Students, when asked "do you know what a virtual Museum is?", a $66.00 \%$ of the participants answered "yes" and a $34.00 \%$ answered "no".

After the teaching intervention $96.00 \%$ of the participants answered in the same question "yes" and $4.00 \%$ "no" (Table 3, Figure 3).

Table 3. Variations in the question if they know what a virtual museum

\begin{tabular}{lcccc}
\hline & & & & Post \\
& Frequency & Percentage & Frequency & Percentage \\
\hline Yes & 66 & $66.00 \%$ & 96 & $96.00 \%$ \\
No & 34 & $34.00 \%$ & 4 & $4.00 \%$ \\
\hline Ensemble & 100 & $100.00 \%$ & 100 & $100.00 \%$ \\
\hline
\end{tabular}

As shown in Table 3, students discovered through their own constribution what a virtual Museum is.

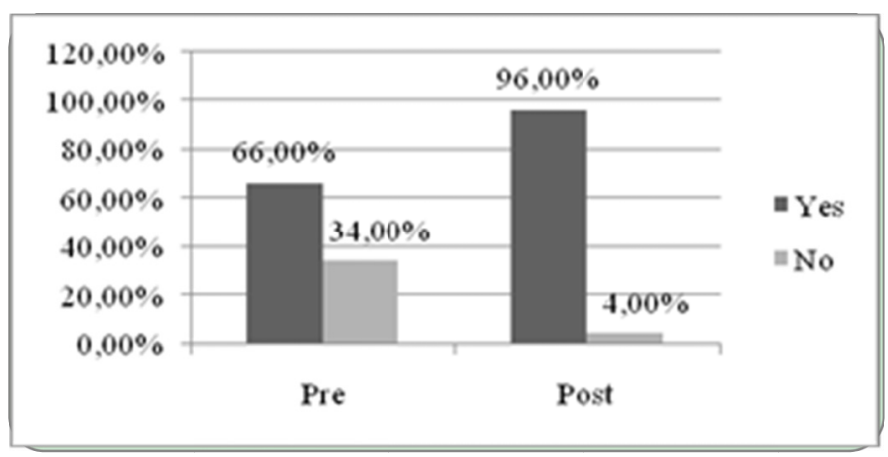

Figure 3. Do you know what a virtual museum is?

Students that took part in the project and survey before teaching intervention when asked "can you construct a virtual Museum using a computer?", a $31.00 \%$ of the participants answered "yes" and a $69.00 \%$ answered "no". 
After the teaching intervention a $97.00 \%$ of the participants answered in the same question "yes" and a $3.00 \%$ answered "no" (Table 4, Figure 4).

Table 4. Variations in ability to construct a virtual museum before and after teaching intervention

\begin{tabular}{llcll}
\hline & \multicolumn{2}{c}{ Pre } & \multicolumn{2}{c}{ Post } \\
& Frequency & Percentage & Frequency & Percentage \\
\hline Yes & 31 & $31.00 \%$ & 97 & $97.00 \%$ \\
No & 69 & $69.00 \%$ & 3 & $3.00 \%$ \\
Ensemble & 100 & $100.00 \%$ & 100 & $100.00 \%$ \\
\hline
\end{tabular}

As shown in Table 4, after the teaching intervention most of the students had learnt how they construct a virtual Museum using a computer.

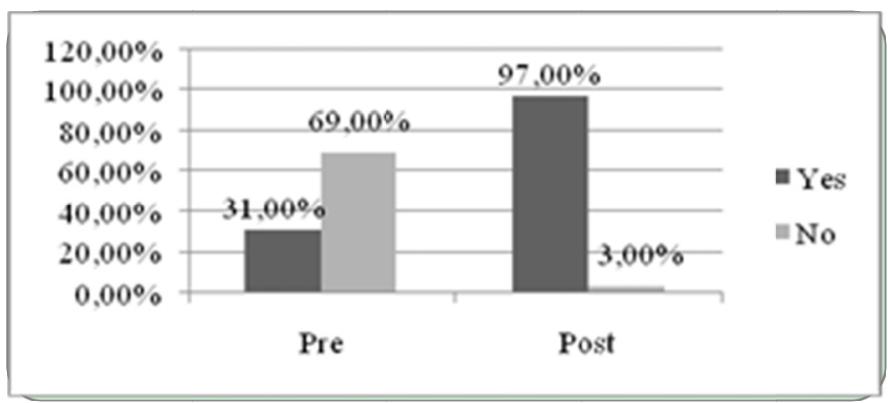

Figure 4. Can you construct a virtual museum using acomputer?

To the question "do you think the promotion of local folk art is important?" a $16.00 \%$ answered "strongly disagree", 22.00\% "disagree", 39.00\% "neither agree nor disagree" the $15.00 \%$ "agree and $8.00 \%$ "strongly agree".

After the teaching intervention a $3.00 \%$ of the participants replied in the same question "strongly disagree", $4.00 \%$ "disagree", 38.00\% "neither agree nor disagree" a 34.00\% "agree” and 21.00\% "strongly agree" (Tab. 5, Fig. 5).

Table 5. Variations on whether the promotion of local folk art is important

\begin{tabular}{lcccc} 
& \multicolumn{2}{c}{ Pre } & & Post \\
& Frequency & Percentage & Frequency & Percentage \\
\hline $\begin{array}{l}\text { Strongly } \\
\text { disagree }\end{array}$ & 16 & $16.00 \%$ & 3 & $3.00 \%$ \\
Disagree & 22 & & & $4.00 \%$ \\
Neither agree or & 39 & $22.00 \%$ & 4 & $38.00 \%$ \\
disagree & & $39.00 \%$ & 34 & $34.00 \%$ \\
Agree & 15 & $15.00 \%$ & 21 & $21.00 \%$ \\
Strongly agree & 8 & $8.00 \%$ & 100 & $100.00 \%$ \\
Ensemble & 100 & $100.00 \%$ & & \\
\hline
\end{tabular}

As shown in Table 5, many of the students think that promoting the local folk Art it is very important. 


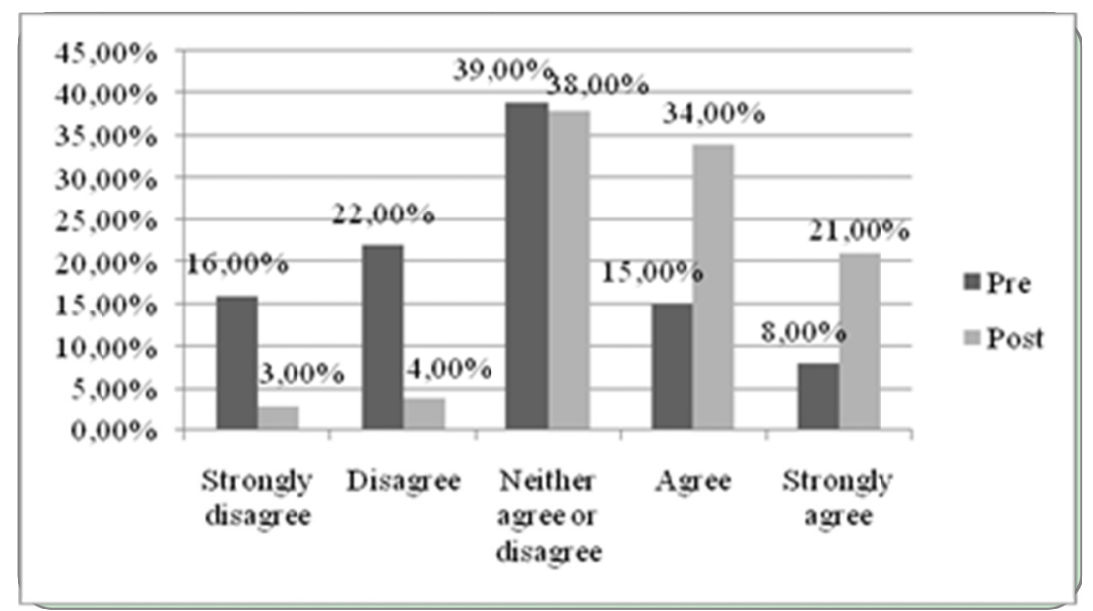

Figure 5. Do you think the promotion of local folk art is important?

To the question "do you think that local folk Art should be taught in secondary education?", a $60.00 \%$ of the participants answered "yes" and a $40.00 \%$ answered "no".

After the teaching intervention the views above differed. As showed, a $80.00 \%$ answered "yes" and $20.00 \%$ replied "no" (Table 6, Figure 6).

Table 6. Variations in the question if local folk art should be taught in secondary education

\begin{tabular}{lcccc}
\hline & Pre & & Post \\
& Frequency & Percentage & Frequency & Percentage \\
\hline Yes & 60 & $60.00 \%$ & 80 & $80.00 \%$ \\
No & 40 & $40.00 \%$ & 20 & $20.00 \%$ \\
Ensemble & 100 & $100.00 \%$ & 100 & $100.00 \%$ \\
\hline
\end{tabular}

As shown in Table 6, after the teaching intervention students think that local folk Art should be taught in secondary education.

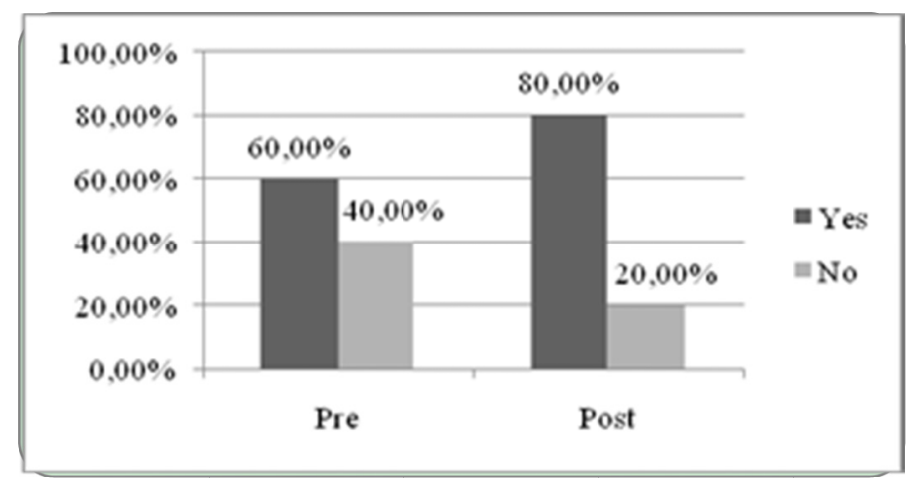

Figure 6. Do you think that local folk art should be taught in secondary education?

When students asked, "do you think the preservation of cultural heritage is important?" before the teaching intervention, a 3.00\% answered "strongly disagree", 9.00\% "disagree", $30.00 \%$ "neither agree nor disagree" the $23.00 \%$ "agree and $35.00 \%$ "strongly agree".

After the teaching intervention a $2.00 \%$ of the participants replied in the same question "strongly disagree", $4.00 \%$ "disagree", $13.00 \%$ "neither agree nor disagree" a 36.00\% "agree" and $45.00 \%$ "strongly agree" (Table 7, Figure 7). 
Table 7. Variations in the question if they think that the preservation of cultural heritage is important

\begin{tabular}{lcccc}
\hline & Pre & & Post \\
& Frequency & Percentage & Frequency & Percentage \\
\hline $\begin{array}{l}\text { Strongly } \\
\text { disagree }\end{array}$ & 3 & $3.00 \%$ & 2 & $2.00 \%$ \\
$\begin{array}{l}\text { Disagree } \\
\text { Neither agree or }\end{array}$ & 9 & & & $4.00 \%$ \\
disagree & & $9.00 \%$ & 4 & $13.00 \%$ \\
Agree & 23 & $30.00 \%$ & 36 & $36.00 \%$ \\
Strongly agree & 35 & $23.00 \%$ & 45 & $45.00 \%$ \\
Ensemble & 100 & $35.00 \%$ & 100 & $100.00 \%$ \\
\hline
\end{tabular}

As shown in Table 7, most of the students agree or strongly agree after the teaching intervention, that the preservation of cultural heritage is important to them.

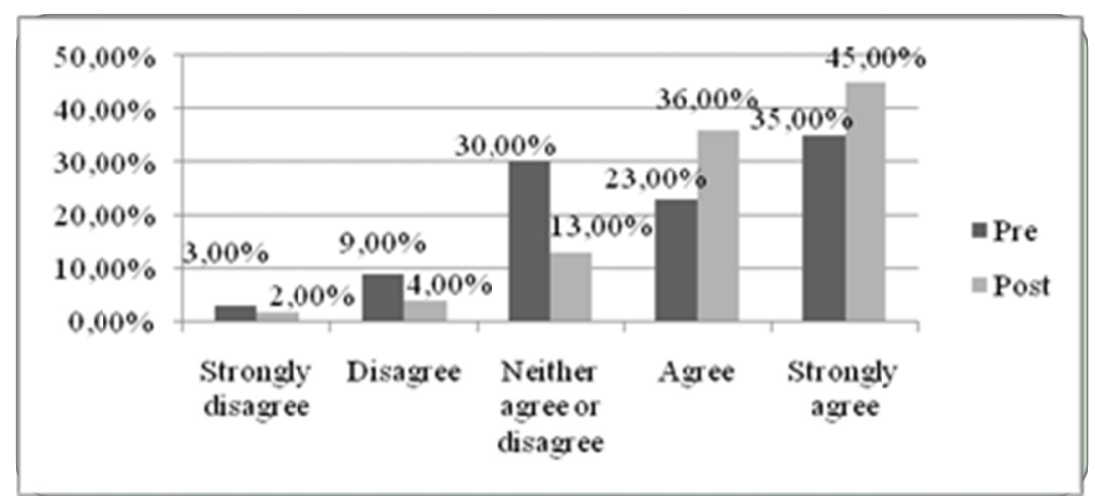

Figure 7. Do you think that the preservation of cultural heritage is important?

When students asked "do you think that a virtual educational Museum can help you to meet local folk Art?" a $82.00 \%$ answered "yes" and $18.00 \%$ "no". After the teaching intervention a $97.00 \%$ replied "yes" and 3.00\% "no" (Table 8, Figure 8).

Table 8. Variations to the question if a virtual educational Museum can help to to meet the local folk art

\begin{tabular}{lcccc}
\hline & \multicolumn{2}{c}{ Pre } & \multicolumn{2}{c}{ Post } \\
& Frequency & Percentage & Frequency & Percentage \\
Yes & 82 & $82.00 \%$ & 97 & $97.00 \%$ \\
No & 18 & $18.00 \%$ & 3 & $3.00 \%$ \\
\hline Ensemble & 100 & $100.00 \%$ & 100 & $100.00 \%$ \\
\hline
\end{tabular}

As shown in Table 8, after the teaching intervention students think that they can meet their local folk Art and learn adout it through a virtual school educational Museum. 


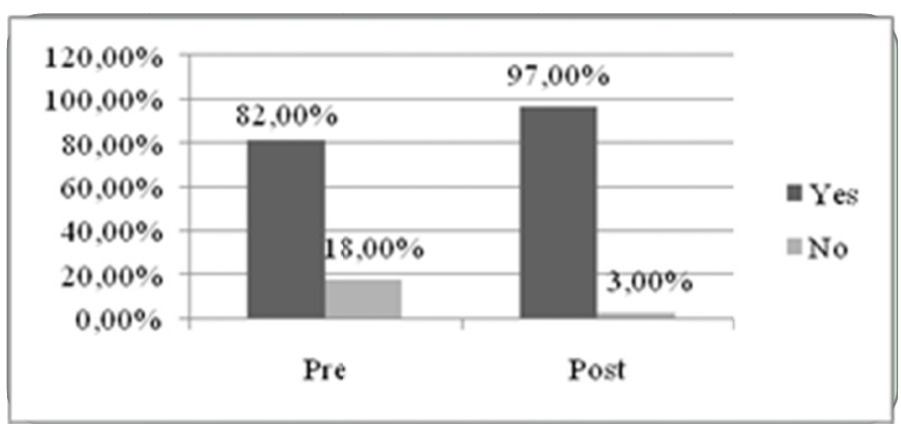

Figure 8. Do you think that a virtual educational museum can help to to meet the local folk Art?

To the question, "would you like to contribute to the dissemination of local folk Art through the construction of a virtual educational Museum?" a $82.00 \%$ answered "yes" and $18.00 \%$ "no". After the teaching intervention a $97.00 \%$ replied "yes" and 3.00\% "no" (Table 9, Figure 9).

Table 9. Variations to the question if they would like to contribute to the dissemination of local folk Art through the construction of a virtual educational Museum

\begin{tabular}{lcccc}
\hline & Pre & & Post \\
& Frequency & Percentage & Frequency & Percentage \\
\hline Yes & 58 & $58.00 \%$ & 85 & $85.00 \%$ \\
No & 42 & $42.00 \%$ & 15 & $15.00 \%$ \\
Ensemble & 100 & $100.00 \%$ & 100 & $100.00 \%$ \\
\hline
\end{tabular}

As shown in Table 9, after the teaching intervention students think that the dissemination of local folk Art is very important and that they would like a lot to contribute to this.

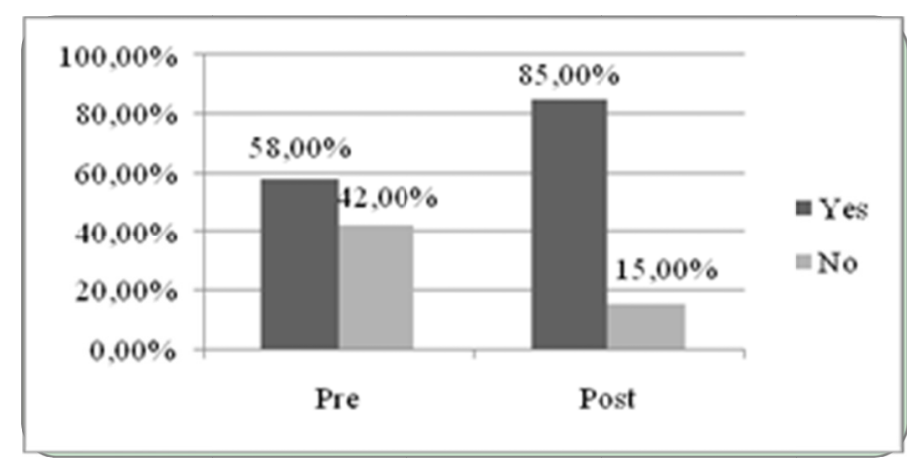

Figure 9. Would you like to contribute to the dissemination of local folk art through the construction of a virtual educational Museum?

To the question "do you think that the virtual educational Popular Culture Museum can help you to understand further the historical continuity of your region?", a $60.00 \%$ of the participants answered "yes" and a $40.00 \%$ answered "no".

After the teaching intervention the views above differed. As showed, a $80.00 \%$ answered "yes" and $20.00 \%$ replied "no" (Table 10, Figure 10).

Table 10. Variations in the question if local folk art should be taught in secondary education

\begin{tabular}{lcccc}
\hline & Pre & & Post \\
& Frequency & Percentage & Frequency & Percentage \\
\hline Yes & 82 & $82.00 \%$ & 96 & $96.00 \%$ \\
No & 18 & $18.00 \%$ & 4 & $4.00 \%$ \\
Ensemble & 100 & $100.00 \%$ & 100 & $100.00 \%$ \\
\hline
\end{tabular}


As shown in Table 10, after the teaching intervention students think that local folk Art should be taught in secondary education.

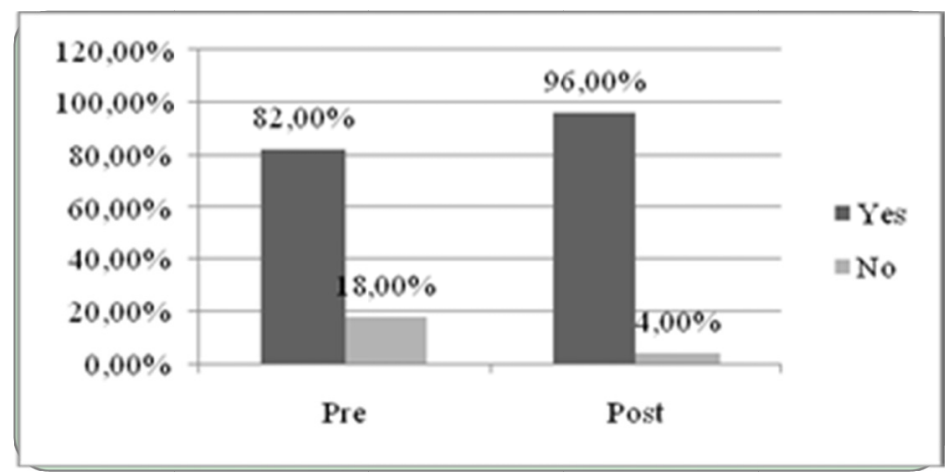

Figure 10. Do you think that local folk Art should be taught in secondary education?

\section{Conclusions}

Arts effect childrens's lives and students through Arts education develop those cognitive abilities that allow him to analyze, describe, assess, interpret and also realize that culture and Art are two interrelated elements (Kampouropoulou-Savvaidou, 2007). The goal of this study was to appoint the students' views on the construction and use of an educational virtual Popular Culture school Museum. The analysis showcased that the majority of students who participated in the school project is positive towards it. It enables teachers to enrich the traditional way of learning with the use of ICT. The majority of students changed their attidude towards local Art, learned more about it and realized the value of preserving cultural heritage. They were helped to understand further the historical continuity of their region to the extent that the majority of them think that local folk Art should be taught in secondary education. Pedagogical Institutes consider that the use and expoitation of ICT provides a cross-curricular approach combined with holistic way of learning. Teachers must use appropriate tools to provide useful information in attractive environment (Kampouropoulou et al., 2011). The new methods in teaching practice, in combination with other elements create a new challenge for future researchers in fearther research on this study (Athanasiadis \& Stefos, 2006).

\section{References}

Archontidis, T., Zympidis, D., Parkosidis, I., \& Mikropoulos, T. (2004). The museum of Odysseus. An interactive virtual museum for teaching mythology at the third grade. Proceedings of th $4^{\text {th }}$ Cogress on Informatics in Education.

Athanasiadis, I., \& Stefos, E. (Eds.) (2006). Interdisciplinary technological approaches. Applications in the High school of Ialyssos (pp. 36-40). Minicipal Library of Ialyssos.

Bernier, R. (2002). The uses of virtual museums: the French viewpoint. Proceedings in the Conference Museums and the Web 2002, Archives and Museum Informatics. Boston, USA.

Dewey, J. (1938/1998). Expeience and education. West Lafayette, Indiana kappa delta Pi.

Dimitrakopoulou, (2002). ICT in Education. Proceedings of the $3^{\text {rd }}$ Confererce on Informatics in Education (pp. 369-374). Athens Kastaniotis.

Girtzi, M., \& Boundidou, A. (2010). Disigning activities by utilizing new technologies to the educational program: Travelling to Aegea of Macedonia for the royal wedding. Proceedings of the $2^{\text {nd }}$ Jellenic Educational Conference. Imathia.

Kampouropoulou, M., Fokiali, P., Athanasiadis, I., \& Stefos, E. (2011). Teaching Art using Technology: The views of High School students in Greece. Review of European Studies, 3(2), 98-109. http://dx.doi.org/10.5539/res.v3n2p98.

Kampouropoulou - Savvaidou, M. (2007). New Technologies and Education Sciences. Athens, Metaichmio.

Matsagouras, I. (2002). Interdisciplinarity and Cross-thematic Curicula: Ways of organizing school knowledge. Review of Educational Affairs, 7, 19-36.

Mikropoulos, A., Diplas, K., Pidelas, P., Chalkidis, A., \& Giakovis. D. (1994). Virtual Reality and Education. A new tool or methodology. Proceedings of the $2^{\text {nd }}$ Conference on Informatics in Education. Athens. 
Mikropoulos, A. (1995). Virtual Reality (VR): Experiences' cognitive tool. Present and Future in the educational software. Methods, tools, kits. Proceedings of the colloquium. Patras.

Rapris, A., \& Rapti, A. (2003). Learning and Teaching in the age of Information-Total approach (Vol. A). Athens.

Rogers, C. (1957). Personal thoughts on teaching and learning (pp. 241-243). Merill-Palmer Quarterly.

Fokiali, P., \& Kampouropoulou, M. (2002). Complementarity dimensions in the relationship of education an cultural heritage. In N. Avramidou (Ed.), Proceedings, $1^{\text {st }}$ Inernational Conference on Vulnerability of $20^{\text {th }}$ century Heritage to Hazardsand Prevention Measures. UNESCO, University of the Aegean, University of Firenze, CICOP, Rhodes.

Fokiali, P., Kampouropoulou, M., \& Konsolas, M. (2003). Sustainable Development, Art and linguistic communication. Teaching children of primary school to plan the future of their country. Pedagogikos Logos.

\section{Copyrights}

Copyright for this article is retained by the author(s), with first publication rights granted to the journal.

This is an open-access article distributed under the terms and conditions of the Creative Commons Attribution license (http://creativecommons.org/licenses/by/3.0/). 